\section{$\underset{\text { hommes }}{\text { \& migrations }}$}

\section{Hommes \& migrations}

Revue française de référence sur les dynamiques

migratoires

1306 | 2014

Ecriture et migration

\title{
Polyphonie narrative
}

\section{Marie Poinsot}

\section{(QpenEdition \\ Journals}

\section{Édition électronique}

URL : http://journals.openedition.org/hommesmigrations/2785

DOI : 10.4000/hommesmigrations.2785

ISSN : 2262-3353

\section{Éditeur}

Musée national de l'histoire de l'immigration

\section{Édition imprimée}

Date de publication : 1 avril 2014

Pagination : 1

ISBN : 978-2-919040-27-8

ISSN : $1142-852 X$

\section{Référence électronique}

Marie Poinsot, « Polyphonie narrative », Hommes \& migrations [En ligne], 1306 | 2014, mis en ligne le 05 août 2014, consulté le 22 septembre 2020. URL : http://journals.openedition.org/hommesmigrations/ 2785 ; DOl : https://doi.org/10.4000/hommesmigrations.2785 


\section{POLYPHONIE NARRATIVE}

par MARIE POINSOT, rédactrice en chef.

S'il est un domaine où les tentatives de contrer les images stéréotypées sur l'immigration ont acquis plus de visibilité et d'audience en France, c'est celui de la littérature et, par extension, les nombreux récits, témoignages, formes d'écriture qui portent sur les parcours et les exils des migrants. Même si la revue édite depuis longtemps des chroniques sur les romans ou les essais qui explorent les voies multiples de la migration, son investissement s'est renforcé depuis la création en 2010 du prix littéraire de la Porte Dorée par le Musée de l'histoire de l'immigration, grâce aux efforts de Mustapha Harzoune et d'Élisabeth Lesne pour construire ensemble des passerelles. Depuis cinq ans, la revue se fait l'écho des belles moissons du prix littéraire et nous montre comment les romans sélectionnés dans l’année nous ouvrent de nouveaux imaginaires sur les mobilités humaines. Julien Delmaire, le lauréat de juin 2014 pour son roman Georgia (Grasset), estime que "Le prix littéraire de la Porte Dorée est une tentative fragile et généreuse d'ajuster les cadrans de notre perception de l'Autre et de l'Ailleurs. C'est un prix courageux et ainsi l'un des plus désirables que je connaisse. Il sélectionne des livres le plus souvent hors des sentiers courus, des langues rabâchées. Il n'a pas peur de sa subjectivité, de son engagement. Il est politique dans le meilleur sens du terme : celui de l'attention à autrui, fût-il étranger... La thématique de l'exil est féconde, elle permet d'aborder les continents les plus intimes, de frôler les plis et replis de l'humain, de dérouler les paysages de la mémoire et d'embrasser le présent".

Cette cohabitation des sciences humaines et de la littérature au sein de la revue lui forge une identité éditoriale "mixte" ouverte aux complémentarités entre des démarches, des terminologies et des enjeux qui éclairent différentes facettes des mêmes

réalités. Au-delà d'une médiation scientifique qui fait sa notoriété, Hommes \& Migrations nous met à l'écoute de ce que la création contemporaine raconte des traversées, des frontières, des déracinements et des enracinements, des altérités et des identités dans un monde pluriel et sous tension, devenu de plus en plus nomade. À la question de savoir si la littérature exprime la voix inaudible des migrants, des sans-papiers, des sans statut installés ou marginalisés, Léonora Miano, présidente du jury de notre prix cette année, répond dans ce numéro: "Aucun [des auteurs de la sélection 2014] n'aurait envie d'être présenté comme un porte-parole ou même un porte-voix. Ce serait trop lourd. Ces textes nous ouvrent sur des réalités qui parfois nous échappent, mais ils restent des invitations à aller voir. Surtout, ne les lisons pas comme sils étaient des espèces de témoignages. Nous passerions à côté du travail de création, qui est la chose la plus importante. Les auteurs nous font traverser un pays de l'imaginaire qui ressemble à celui que nous connaissons et c'est pour cela que nous nous y attachons. C'est la noblesse du travail littéraire : la création."

La revue a fait coïncider cette $5^{e}$ édition du prix littéraire avec la parution d'un dossier issu d'un colloque transdisciplinaire tenu à l'université de Paris-VIII de Saint-Denis, les 11 et 12 mai 2012, qui a exploré les nombreuses démarches pour "écrire la migration". En analysant les liens entre écriture et migrations, les articles de ce dossier déconstruisent les ressorts idéologiques et méthodologiques des différents actes de narration qui interviennent selon le profil des protagonistes et selon les domaines dans lesquels les récits produits vont s'inscrire. Ils identifient aussi les conséquences que ces narrations engendrent sur les temporalités, les expériences vécues et les émotions qui recomposent les migrations et leur donnent du sens. Tout cela, pour lire les récits avec des lunettes averties. 